\title{
ALPHA-PARTICLE EMISSION FROM CONTAMINANTS IN COUNTER MATERIALS
}

\author{
Barakat AL-BATAINA * and Joachim JÄNECKE \\ Department of Physics, The University of Michigan, Ann Arbor, Michigan 48109, USA
}

Received 4 November 1986

Energy spectra of surface activities from thorium and uranium contaminants have been investigated for typical counter materials. Soft-tempered stainless steel with a rate of $1.2 \pm 0.1 \mathrm{a}$-particles emitted per $100 \mathrm{~cm}^{2}$ in one hour was found better than other stainless steel and far better than brass and aluminum. Energy spectra provide information about the contaminating activity and about its depth profile. Thorium, uranium and ${ }^{210} \mathrm{~Pb}$ contamination was also observed for thin sources of other materials including isotopically enriched materials.

\section{Introduction}

Detailed knowledge about external and internal background is required when investigating low-level radiation phenomena. This includes knowledge about the origin of background radiation and its suppression. Ultralow background $\beta-\gamma$ spectrometers have been given special attention recently (see e.g. refs. $[1,2]$ ). Less information is available for alpha spectrometers, especially about the radioactive contamination of counter materials and the energy dependence of these activities, and the information is less readily accessible.

The choice of counter materials became an important consideration in a recent study of long-lived alpha emitters $[3,4]$. Attention was given to the surface activities mostly from ${ }^{232} \mathrm{Th}$ and ${ }^{238} \mathrm{U}$ contaminants and their daughter products in stainless steel, brass, and aluminum, and energy spectra were measured. Experimental considerations are presented in sect. 2 . The results are given in sect. 3 and discussed in sect. 4 together with a comparison to known data from the literature.

\section{Experimental procedures}

A cylindrical proportional counter with a diameter of $10 \mathrm{~cm}$ was used for the measurements. A gold-plated tungsten anode wire with a diameter of $50 \mu \mathrm{m}$ defined the length of the active volume. The materials to be tested were rolled into the shape of a cylinder and inserted inside the cathode cylinder. The active area was typically $1550 \mathrm{~cm}^{2}$. A continuous flow of a PTEN gas

\footnotetext{
* Now at: Department of Physics, Yarmouk University, Irbid, Jordan.
}

mixture (90\% $\mathrm{Ar}, 10 \% \mathrm{CH}_{4}$ ) was maintained, and the pressure was regulated slightly above 1 atm. Anode signals were amplified with a charge-sensitive preamplifier and a spectroscopy amplifier with pulse shaping time constants of $5 \mu \mathrm{s}$ for integration and differentiation. They were recorded in a multichannel analyzer for subsequent computer processing.

The electric field near the cathode was sufficiently high to ensure complete collection of the electrons produced in the interaction of $\alpha$-particles with the counter gas. A gas multiplication factor $M \approx 1.3$, only slightly above the ion chamber region, was employed. A point source of ${ }^{210} \mathrm{Po}$ and thin areal sources of ${ }^{238} \mathrm{U}$ and ${ }^{147} \mathrm{Sm}$ were used for energy calibration. The thin sources of $50-300 \mu \mathrm{g} / \mathrm{cm}^{2}$ thickness were prepared by evaporation of alcoholic solutions, by molecular plating and by electrodeposition. The energy resolution was typically 3-6\%.

Suppression of external background from cosmic radiation and $\gamma$-rays from the environment was achieved by shielding the counter with $1400 \mathrm{~kg}$ of lead and old iron. This led to a significant reduction of the background in the region below $2 \mathrm{MeV}$ where $\gamma$-rays appear to be the main source of background. The number of recorded events above $2 \mathrm{MeV}$ was also significantly reduced to a very small level which is believed to come almost exclusively from radioactive contaminants in the counter and source materials, the object of the present study.

\section{Experimental results}

Figs. 1, 2 and 3 display $\alpha$-particle spectra from contaminants in thick sources of aluminum, brass, and stainless steel. The source area is about $1550 \mathrm{~cm}^{2}$. The 


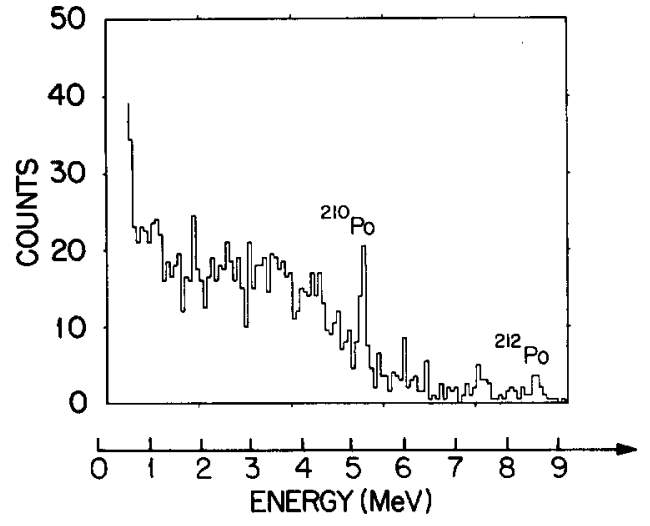

Fig. 1. Energy spectrum of $\alpha$-particle emitting contaminants from a large-area source of aluminum $(t=5.2 \mathrm{~h})$.

continuous spectrum for aluminum extends to about 8.8 $\mathrm{MeV}$ with a significant drop over the interval 4-6 MeV. A discrete line is present at $5.3 \mathrm{MeV}$, and weak broad bumps at 7.6 and $8.7 \mathrm{MeV}$. The spectra for brass and stainless steel also extends to about $8.8 \mathrm{MeV}$ with a much sharper falloff at $6.8 \mathrm{MeV}$. Broader bumps are seen at $8.7 \mathrm{MeV}$ particularly for the brass spectrum which also displays several discrete lines from about 4.0 to $6.7 \mathrm{MeV}$. The increase of all three spectra below about $1 \mathrm{MeV}$ is not due to $\alpha$-particles but results from residual external $\gamma$-ray background radiation.

The areal count rates for energies from 1 to $9 \mathrm{MeV}$ are listed in table 1 for intervals of $1 \mathrm{MeV}$ together with the total count rates over the entire range. The table includes results for two types of stainless steel and for stainless steel treated with nitric acid. The two types of stainless steel (Type 304; Enduro Republic Co., Ohio) differ only in their surface structure. The chemical composition is $\mathrm{Fe}(65-70 \%), \mathrm{C}(0.08 \%$ max.), $\mathrm{Mn}(2 \%$ max.), P (0.045\% max.), S (0.030\% max.), Si (1\% max.), $\mathrm{Cr}(18-20 \%)$, and $\mathrm{Ni}(8-10.5 \%)$. Type I has a $2 \mathrm{~B}$ finish which is not shiny (cold rolled and annealed). Type II

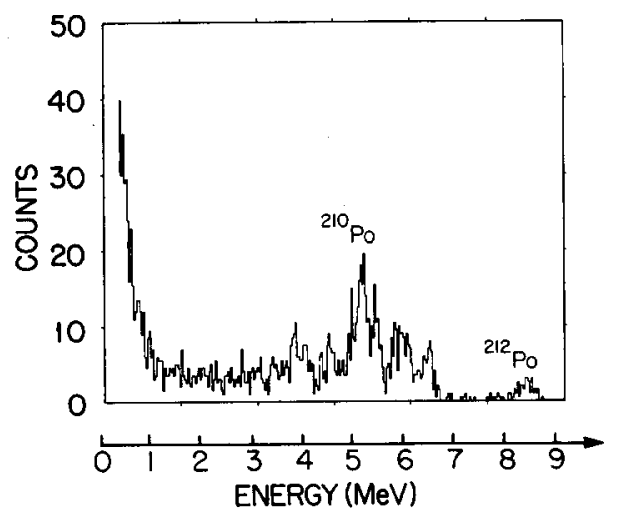

Fig. 2. Energy spectrum of $\alpha$-particle emitting contaminants from a large-area source of brass $(t=10 \mathrm{~h})$.

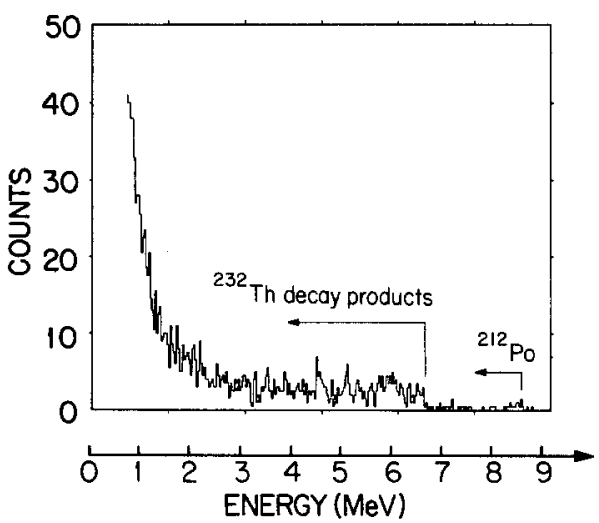

Fig. 3. Energy spectrum of $\alpha$-particle emitting contaminants from a large-area source of stainless steel (type II; $t=100 \mathrm{~h}$ ).

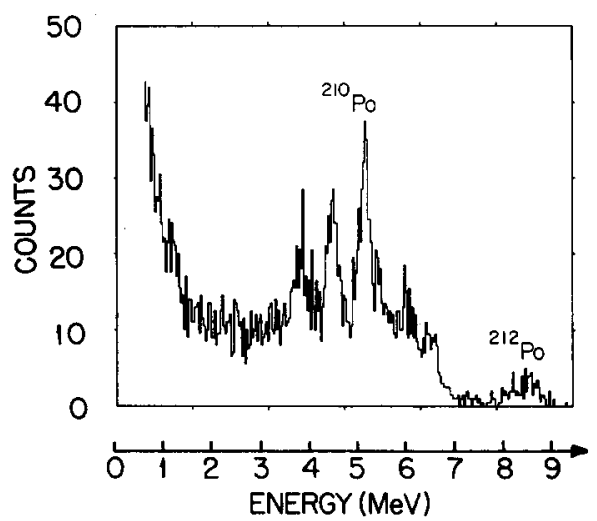

Fig. 4. Energy spectrum of $\alpha$-particle emitting contaminants from a thin large-area source of natural neodymium oxyde on a stainless steel backing ( $\rho x \approx 63 \mu \mathrm{g} \mathrm{cm}^{-2} ; t=26.6 \mathrm{~h}$ ).

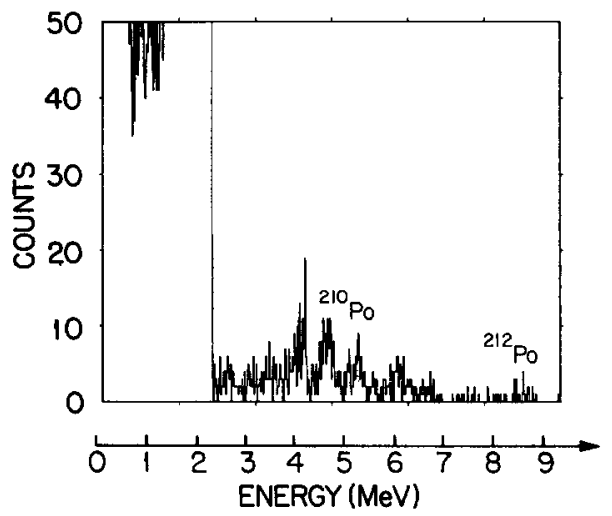

Fig. 5. Energy spectrum of $\alpha$-particle emitting contaminants from a thin large-area source of isotopically enriched samarium chloride on a stainless steel backing $\left({ }^{148} \mathrm{Sm} 96.4 \%,{ }^{147} \mathrm{Sm} 1.3 \%\right.$; $\rho x \approx 57 \mu \mathrm{g} \mathrm{cm}^{-2} ; t=22 \mathrm{~h}$ ). 
Table 1

Energy dependence of the rate of $\alpha$-particle emission from the surface of various materials

\begin{tabular}{llllll}
\hline $\begin{array}{l}\text { Energy } \\
\text { range } \\
{[\mathrm{MeV}]}\end{array}$ & Aluminum & Brass & Stainless steel I & Stainless steel II & $\begin{array}{l}\text { Treated stainless } \\
\text { steel I }\end{array}$ \\
\cline { 2 - 6 } & Count rate per area and energy [counts $\left.\mathrm{MeV}^{-1} \mathrm{~cm}^{-2} \cdot \mathrm{h}^{-1}\right]$ & & $(19.5 \pm 1.5) \times 10^{-3}$ \\
\hline $1-2$ & $(6.2 \pm 0.4) \times 10^{-2}$ & $(2.0 \pm 0.2) \times 10^{-2}$ & $(12.9 \pm 1.2) \times 10^{-3}$ & $(5.1 \pm 0.3) \times 10^{-3}$ & $(3.5 \pm 0.5) \times 10^{-3}$ \\
$2-3$ & $(5.7 \pm 0.4) \times 10^{-2}$ & $(1.4 \pm 0.1) \times 10^{-2}$ & $(2.8 \pm 0.5) \times 10^{-3}$ & $(1.9 \pm 0.2) \times 10^{-3}$ & $(2.4 \pm 0.5) \times 10^{-3}$ \\
$3-4$ & $(5.8 \pm 0.4) \times 10^{-2}$ & $(1.9 \pm 0.1) \times 10^{-2}$ & $(2.4 \pm 0.5) \times 10^{-3}$ & $(1.3 \pm 0.1) \times 10^{-3}$ & $(2.4 \pm 0.5) \times 10^{-3}$ \\
$4-5$ & $(4.3 \pm 0.3) \times 10^{-2}$ & $(2.1 \pm 0.1) \times 10^{-2}$ & $(2.2 \pm 0.5) \times 10^{-3}$ & $(1.2 \pm 0.1) \times 10^{-3}$ & $(2.2 \pm 0.5) \times 10^{-3}$ \\
$5-6$ & $(2.4 \pm 0.3) \times 10^{-2}$ & $(3.7 \pm 0.2) \times 10^{-2}$ & $(2.3 \pm 0.5) \times 10^{-3}$ & $(1.0 \pm 0.1) \times 10^{-3}$ & $(1.4 \pm 0.5) \times 10^{-3}$ \\
$6-7$ & $(1.0 \pm 0.1) \times 10^{-2}$ & $(1.4 \pm 0.1) \times 10^{-2}$ & $(2.7 \pm 0.5) \times 10^{-3}$ & $(1.1 \pm 0.1) \times 10^{-3}$ & $(3.3 \pm 1.4) \times 10^{-4}$ \\
$7-8$ & $(6.5 \pm 1.0) \times 10^{-3}$ & $(1.0 \pm 0.3) \times 10^{-3}$ & $(4.6 \pm 2.7) \times 10^{-4}$ & $(2.0 \pm 0.7) \times 10^{-4}$ & $(4.6 \pm 2.0) \times 10^{-4}$ \\
$8-9$ & $(5.3 \pm 1.0) \times 10^{-3}$ & $(4.4 \pm 0.6) \times 10^{-3}$ & $(5.3 \pm 2.0) \times 10^{-4}$ & $(2.0 \pm 0.7) \times 10^{-4}$ & \\
\hline \multicolumn{7}{c}{ Count rate per area [counts cm $\left.{ }^{-2} \mathrm{~h}^{-1}\right]$} & & & $(1.20 \pm 0.07) \times 10^{-2}$ & $(3.22 \pm 0.22) \times 10^{-2}$ \\
\hline $1-9$ & $(2.66 \pm 0.15) \times 10^{-1}$ & $(1.29 \pm 0.07) \times 10^{-1}$ & $(2.64 \pm 0.20) \times 10^{-2}$ &
\end{tabular}

has a $4 \mathrm{~B}$ finish which is shiny (cold rolled, annealed, and soft tempered). The results for the two types of stainless steel were confirmed and verified for several sources each.

Figs. 4, 5 and 6 display $\alpha$-particle spectra for contaminants in thin sources applied to stainless steel backings. They are meant to demonstrate the degree of contamination from $\mathrm{Th}$ and $\mathrm{U}$ and their decay products in various chemical compounds. Fig. 4 shows a spectrum from a source of natural neodymium $(99.99 \%$ pure) prepared by evaporation of an alcoholic solution. The lines above $4 \mathrm{MeV}$ are indicative of $\mathrm{Th}$ and $\mathrm{U}$ contaminants. Fig. 5 shows a spectrum from a source of isotopically enriched samarium prepared by molecular plating. The spectrum above the strong $\alpha$-line at 2.2 $\mathrm{MeV}$ from the decay of ${ }^{147} \mathrm{Sm}$ is again indicative of $\mathrm{Th}$ and $U$ contaminants. Fig. 6 shows a spectrum from a source of natural platinum prepared by electrodeposition. The $\alpha$-line at $3.2 \mathrm{MeV}$ is that from the $\alpha$-decay of ${ }^{190} \mathrm{Pt}$. The spectrum also shows a line at $5.3 \mathrm{MeV}$

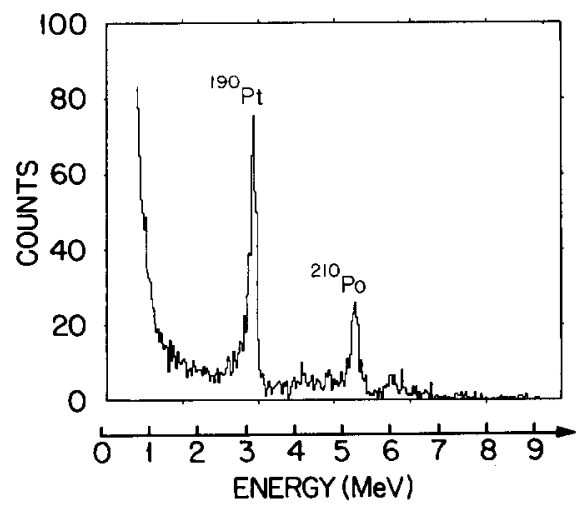

Fig. 6. Energy spectrum of $\alpha$-particles from a thin large-area source of platinum on a stainless steel backing $(\rho x \approx 310$ $\mu \mathrm{g} \mathrm{cm}^{-2} ; t=100 \mathrm{~h}$ ). presumably from the $\alpha$-decay of ${ }^{210}$ Po which is the decay product of ${ }^{210} \mathrm{~Pb}\left(\mathrm{RaD}: T_{1 / 2}=22 \mathrm{yr}\right.$ ).

\section{Discussion}

Table 1 shows that the surface activities from alpha emitting contaminants differ greatly for different materials. Stainless steel II was found superior to brass and aluminum by factors of 10-20. Interestingly, stainless steel II has only one-half the surface activity of stainless steel $\mathrm{I}$. This is surprising since the materials have identical chemical composition. It is concluded that presumably volatile surface contaminants are removed in stainless steel II by the additional heat treatment. The range of $\alpha$-particles in steel is only on the order of $10-20 \mu \mathrm{m}$. Only contaminants within this thickness near the surface will therefore contribute to

Table 2

Rate of $\alpha$-particle emission from the surface of various materials

\begin{tabular}{|c|c|c|c|c|c|}
\hline \multirow[t]{2}{*}{ Material } & \multicolumn{5}{|c|}{$\begin{array}{l}\text { Count rate per area } \\
\text { [counts } 100^{-1} \mathrm{~cm}^{-2} \mathrm{~h}^{-1} \text { ] }\end{array}$} \\
\hline & a) & b) & c) & d) & This work \\
\hline \multirow[t]{2}{*}{ Aluminum } & 31 & 5.8 & 5.0 & & $27 \pm 2$ \\
\hline & & 43 & 23.5 & & $13 \pm 1$ \\
\hline Brass & 5 & & 7 & & $13 \pm 1$ \\
\hline \multirow{2}{*}{$\begin{array}{l}\text { Stainless } \\
\text { steel }\end{array}$} & 3 & & 6.0 & & $2.6 \pm 0.2$ \\
\hline & & & 2.6 & & $1.2 \pm 0.1$ \\
\hline \multirow[t]{3}{*}{ Solder } & 2800 & & 80 & $2000-6000$ & \\
\hline & & & 600 & 42000 & \\
\hline & & & $5(\mathrm{Ag})$ & 78000 & \\
\hline
\end{tabular}

a) Ref. [5].

b) Ref. [6]

c) Ref. [7]

d) Ref. [8] 
the background. The last column in table 1 shows the results for stainless steel treated with nitric acid as a test of its purity. Nitric acid is one of the solvents used in the preparation of thin sources on stainless steel backings. There is no apparent increase or decrease of the surface activities.

Table 2 displays a comparison between the energy integrated surface activities from this work and results reported in the literature [5-8]. The comparison is slightly influenced by the fact that different energy thresholds were used. A threshold of $1 \mathrm{MeV}$ was used in the present work because the increase in count rate at lower energies is believed to be the result of external background radiation. Thresholds of $0.3 \mathrm{MeV}[5], \geq 1.3$ $\mathrm{MeV}[6,8]$, and an unknown but presumably similar value [7] were used in the other work.

The results for aluminum, brass and stainless steel are basically in agreement with each other. One has to keep in mind that the concentration of contaminants varies with origin, supplier, the degree of purity, radon adsorption and the surface treatment of the materials. This seems to be particularly the case for aluminum. The slightly increased value for brass found in the present work seems to be the result of an additional contamination in the surface (depth about $1 \mu \mathrm{m}$ ) presumably introduced by a surface treatment. The surface activity for stainless steel II (see above) seems to be lower than that for other stainless steels.

Included in table 2 are results for various types of soft solder which were given special attention recently
$[7,8]$. The Sn component in solder seems to be responsible for high surface count rates.

Energy integrated surface activities for numerous other materials have been reported both for $\alpha$-emission $[5-7]$ and $\beta$-emission [6,9]. The latter are usually $2-10$ times higher than the former. Stainless steel is useful for counter construction because it is among the conducting materials with the lowest surface activities. However, even lower surface activities were observed [7,9] for several plastic materials, particularly polyethylene and polystyrene, and it has been recommended [9] to use gold-plated plastics for counter construction. Results for aluminized mylar have not been reported.

Alpha-particle energy spectra provide information about the identity of contaminating activities and also about the depth profile. Very little such information is available in the literature.

Fig. 7 schematically the $\alpha$-particle spectra for ${ }^{238} U$ and ${ }^{232} \mathrm{Th}$ and their decay products assumed to be in secular equilibrium. The two spectra provide a signature for these contaminants. The $7.7 \mathrm{MeV}$ line from the decay of ${ }^{214} \mathrm{Po}$ and the $8.8 \mathrm{MeV}$ line from the decay of ${ }^{212} \mathrm{Po}$ are most characteristic for the ${ }^{238} \mathrm{U}$ and ${ }^{232} \mathrm{Th}$ decay chains, respectively.

Line spectra with widths of less than $200-300 \mathrm{keV}$ (fwhm) will be observed for source thicknesses below about $700 \mu \mathrm{g} / \mathrm{cm}^{2}$. An example is shown in fig. 6 where the source thickness for $\mathrm{Pt}$ and the contaminant is about $500 \mu \mathrm{g} / \mathrm{cm}^{2}$ (about $0.2 \mu \mathrm{m}$ ). With increasing source thickness the lines will develop low energy tails

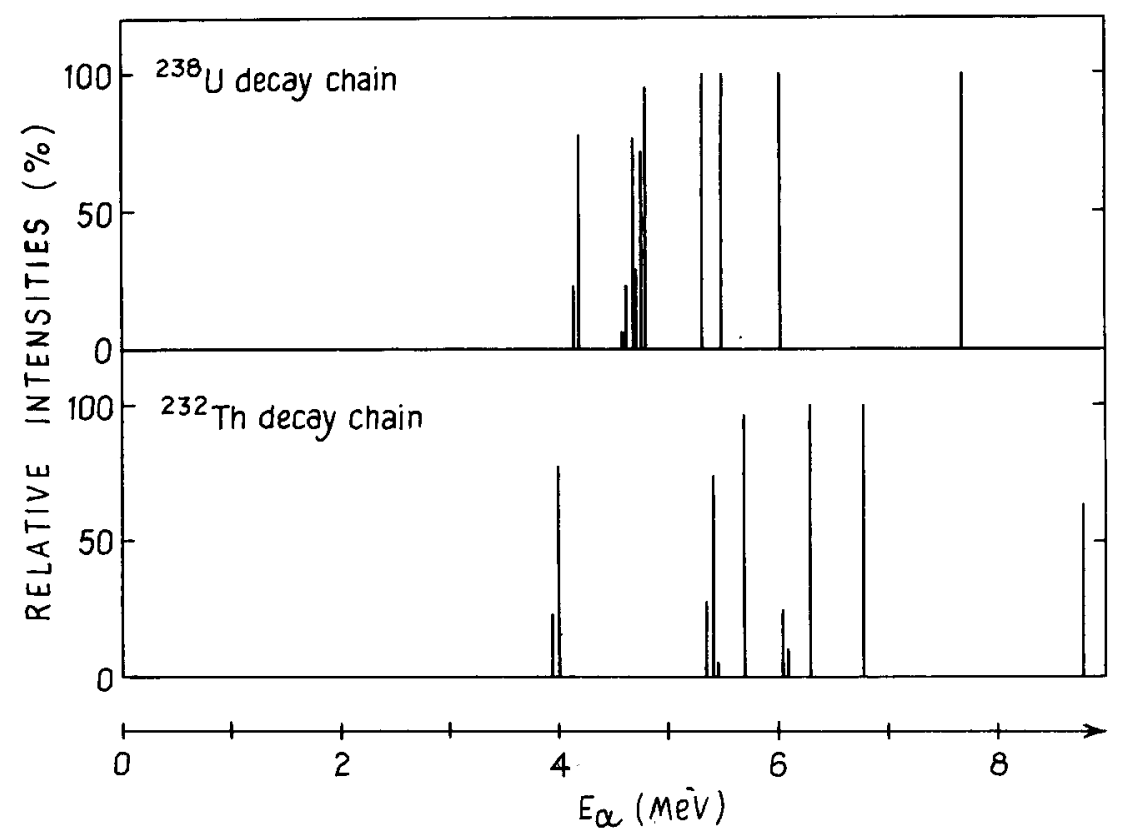

Fig. 7. Calculated $\alpha$-particle energy spectra for ${ }^{238} \mathrm{U}$ and ${ }^{232} \mathrm{Th}$ and their decay products in secular equilibrium. 
which will become wider and wider. The extreme situation is reached for an infinite source thickness where the decaying nuclei are assumed to be uniformly distributed throughout a layer near the surface greater than the range of the $\alpha$-particles which is typically $20 \mathrm{mg} / \mathrm{cm}^{2}$ or $25 \mu \mathrm{m}$. The count rate per area is given in this extreme by

$\frac{\mathrm{d}^{2} n}{\mathrm{~d} A \mathrm{~d} t}=\frac{1}{4} N_{0} R=\frac{1}{4}\left(\frac{N_{0}}{\rho}\right)(R \rho)$,

where $N_{0}$ and $N_{0} / \rho$ are specific activities (in decays $\mathrm{cm}^{-3} \mathrm{~s}^{-1}$ or decays $\mathrm{g}^{-1} \mathrm{~s}^{-1}$ ) and $R$ and $R \rho$ are the ranges in the material (in $\mathrm{cm}$ of $\mathrm{g} \mathrm{cm}^{-2}$ ). The energy distribution of monoenergetic $\alpha$-particles is given by

$$
\frac{\mathrm{d}}{\mathrm{d} E}\left(\frac{\mathrm{d}^{2} n}{\mathrm{~d} A \mathrm{~d} t}\right)=\frac{1}{4} N_{0}\left(-\frac{\mathrm{d} E}{\mathrm{~d} x}\right)^{-1}=\frac{1}{4} \frac{N_{0}}{\rho}\left(-\frac{\mathrm{d} E}{\rho \mathrm{d} x}\right)^{-1}
$$

where $(-\mathrm{d} E / \mathrm{d} x)$ and $(-\mathrm{d} E / \rho \mathrm{d} x)$ are the energy losses (in $\mathrm{MeV} \mathrm{cm}{ }^{-1}$ or $\mathrm{MeV} \mathrm{g}^{-1} \mathrm{~cm}^{2}$ ). Appropriate superpositions have to be constructed when more than one discrete $\alpha$-line is present. Fig. 8 shows as an example a spectrum calculated on the assumption that ${ }^{232} \mathrm{Th}$ and its decay products in secular equilibrium are uniformly distributed in a thick $\mathrm{Ni}$ foil. The specific activity is taken as $N_{0} / \rho=1$ decay $\mathrm{g}^{-1} \mathrm{~s}^{-1}$ for ${ }^{232} \mathrm{Th}$. Ideal detector resolution is assumed. The averaged spectrum falls off smoothly from about 5 to $6.5 \mathrm{MeV}$ followed by a constant tail of $8.8 \mathrm{MeV}$.

Using eq. (1) it follows that brass and aluminum contain contaminants with specific activities of $N_{0} / \rho=$ $(1-5) \times 10^{-2}$ decays $\mathrm{g}^{-1} \mathrm{~s}^{-1}$, at least near the surface. The specific activities for stainless steel are $N_{0} / \rho=$ $(1-3) \times 10^{-3}$ decays $\mathrm{g}^{-1} \mathrm{~s}^{-1}$.

The background spectrum of fig. 1 (see also table 1) for aluminum displays a continuous spectrum with a sharp line at $5.3 \mathrm{MeV}$. This line is from the decay of ${ }^{210} \mathrm{Po}$ which is presumably in secular equilibrium with ${ }^{210} \mathrm{~Pb}\left(\mathrm{RaD} ; T_{1 / 2}=22.3 \mathrm{y}\right)$. It follows from the width of the line that ${ }^{210} \mathrm{~Pb}$ must be contained in a thin layer of

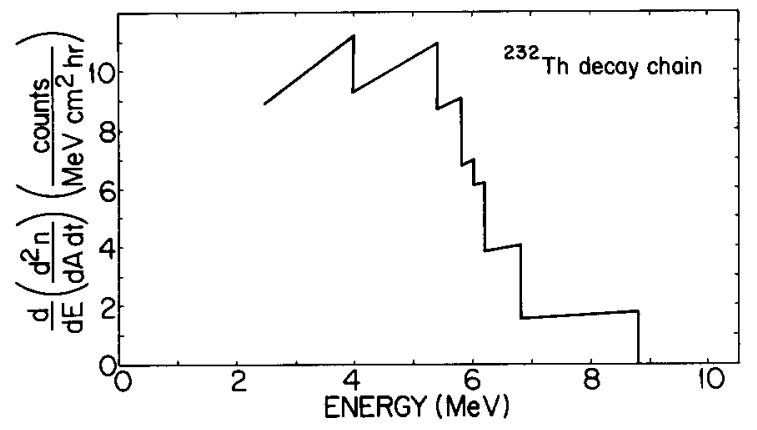

Fig. 8. Calculated $\alpha$-particle energy spectrum for ${ }^{232} \mathrm{Th}$ and its decay products in secular equilibrium distributed uniformly in a thick Ni foil $\left(N_{0} / \rho=1\right.$ decay $\left.g^{-1} \mathrm{~s}^{-1}\right)$. maximum thickness $280 \mu \mathrm{g} / \mathrm{cm}^{2}(1.0 \mu \mathrm{m})$ near the surface. Its presence may be the result of adsorption of ${ }^{222} \mathrm{Rn}$ on the surface $[9,10]$. The slow decrease of the continuous distribution from about 4.0 to $5.5 \mathrm{MeV}$ and the broad bumps at 7.6 and $8.7 \mathrm{MeV}$ suggest that the material contained both ${ }^{238} \mathrm{U}$ and ${ }^{232} \mathrm{Th}$ and their decay products essentially uniformly distributed within its volume (at least within a surface layer of about $50 \mu \mathrm{m}$ ).

The background spectrum of fig. 2 (see also table 1) for brass displays a continuous spectrum with several lines mostly between 5.3 and $6.8 \mathrm{MeV}$. The line at 5.3 $\mathrm{MeV}$ is particularly intense and again suggests the presence of ${ }^{210} \mathrm{Po}$ as decay product of ${ }^{210} \mathrm{~Pb}$ in a thin layer of maximum thickness $500 \mu \mathrm{g} / \mathrm{cm}^{2}(0.6 \mu \mathrm{m})$ near the surface. The other lines suggest the presence of ${ }^{232} \mathrm{Th}$ and its decay products in approximate secular equilibrium in a surface layer of similar thickness. The origin of these additional surface contaminants is unclear. The continuous spectrum underlying these lines and at lower energy suggests the presence of additional ${ }^{232} \mathrm{Th}$ with decay products in deeper layers but with lower concentration. The absence of $\alpha$-particles at and below $7.6 \mathrm{MeV}$ indicates that ${ }^{238} \mathrm{U}$ apparently contributes little to the background.

The background spectrum of fig. 3 (see also table 1) for stainless steel displays a continuous spectrum without discrete lines. The sudden decrease in count rate at $6.7 \mathrm{MeV}$ combined with the bump below 8.7 $\mathrm{MeV}$ and the absence of a bump below $7.6 \mathrm{MeV}$ suggests again that the contamination is predominantly from ${ }^{232} \mathrm{Th}$ and its decay products. The spectrum resembles the calculated spectrum for a uniform distribution of decaying nuclei of fig. 8 only moderately well. This seems to indicate that even here an increased concentration of $\alpha$-decaying contaminants is present near the surface $\left(<20 \mathrm{mg} / \mathrm{cm}^{2} ;<25 \mu \mathrm{m}\right)$.

The shape of the spectra displayed in figs. 1, 2 and 3 is by no means fully understood. However, there are clear indications that $\alpha$-emitting contaminants are sometimes concentrated close to the surface and are not always uniformly distributed throughout the volume. Aspects of this behavior have been recognized earlier [9], and cleaning of surfaces to remove surface layers enriched in contaminants has been recommended.

Figs. 4, 5 and 6 show the presence of radioactive contaminants in various other materials. Figs. 4 and 5 demonstrate the presence of decay products of ${ }^{232} \mathrm{Th}$ and ${ }^{238} \mathrm{U}$. They are not in secular equilibrium which is presumably the result of the chemical history. The broad group near $4.7 \mathrm{MeV}$ is from the ${ }^{238} \mathrm{U}$ decay chain but the absence of the $7.6 \mathrm{MeV}$ line from ${ }^{216} \mathrm{Po}$, also a member of the ${ }^{238} \mathrm{U}$ decay chain, is puzzling. The broad line below $8.7 \mathrm{MeV}$ and the line below $6.8 \mathrm{MeV}$ are clearly from ${ }^{212} \mathrm{Po}$ and ${ }^{216} \mathrm{Po}$, respectively, members of the ${ }^{232} \mathrm{Th}$ decay chain. The line at $5.3 \mathrm{MeV}$ from ${ }^{210} \mathrm{Po}$ is especially strong in the spectrum of natural $\mathrm{Nd}$, fig. 4 , 
again suggesting the presence of ${ }^{210} \mathrm{~Pb}$ contamination. Most of the contaminants are believed to be contained in the source material, but contributions from the chemicals used in the preparation of the sources cannot be excluded. The specific background activities $N_{0} / \rho$ for the above $\mathrm{Nd}$ and enriched $\mathrm{Sm}$ sources were found to be $(1.3 \pm 0.4)$ and $(0.3 \pm 0.2)$ decays $\mathrm{g}^{-1} \mathrm{~s}^{-1}$, respectively. The concentration of contaminating nuclei (ratio of the number of contaminant nuclei to $\mathrm{Nd}$ or $\mathrm{Sm}$ nuclei) depends strongly on the assumed contaminant half-lives and ranges for $\mathrm{Nd}$ from as low as $2.8 \times 10^{-14}$ (assuming $T_{1 / 2}=2 \mathrm{yr}$ ) to as high as $1.4 \times 10^{-5}$ (assuming $T_{1 / 2}=10^{9} \mathrm{yr}$ ). For $\mathrm{Sm}$ the concentrations are smaller by a factor $1 / 4$.

The spectrum for the natural $\mathrm{Pt}$ source of fig. 6 displays a line at $5.3 \mathrm{MeV}$ presumably from ${ }^{210} \mathrm{Po}$. The concentration of contaminating nuclei can be estimated by comparing its activity to that of ${ }^{190} \mathrm{Pt}$ which has a $0.013 \%$ natural isotopic abundance. At the time of the measurement the ratio of ${ }^{210} \mathrm{Po}$ to $\mathrm{Pt}$ nuclei was extremely small, $(3 \pm 1) \times 10^{-17}$. The decay of ${ }^{210} \mathrm{Po}$ and/or the formation from the decay of the parent nucleus ${ }^{210} \mathrm{~Pb}$ changes the above ratio as a function of time. Indeed, another spectrum measured about $1.8 \mathrm{yr}$ after the source was made, displays a significant increase in ${ }^{210} \mathrm{Po}$ with an intensity ratio for the ${ }^{210} \mathrm{Po}$ to ${ }^{190} \mathrm{Pt}$ lines exceeding unity. The number of ${ }^{210} \mathrm{Po}$ nuclei (in secular equilibrium with ${ }^{210} \mathrm{~Pb}$ ) to $\mathrm{Pt}$ nuclei is estimated at $(13 \pm 2) \times 10^{-17}$ which implies an initial ratio of ${ }^{210} \mathrm{~Pb}$ to $\mathrm{Pt}$ nuclei of $(8 \pm 2) \times 10^{-15}$. The origin of ${ }^{210} \mathrm{~Pb}$ is probably from exposure to radon gas, ${ }^{222} \mathrm{Rn}$, with which the platinum was in contact during its history. Similar effects have been reported recently [10] for thin layers of other materials.

\section{Summary}

Surface activities from thorium, uranium and ${ }^{210} \mathrm{~Pb}$ contaminants in aluminum, brass and stainless steel have been investigated and were found in agreement with values reported in the literature. Soft-tempered stainless steel was observed to give the lowest count rates per area. The measurement of energy spectra was found to provide a powerful tool for identifying the nature of the contaminating activities and for their depth profiles. There are clear indications that $\alpha$-emitting contaminants are often concentrated in a layer of 1 $\mu \mathrm{m}$ thickness near the surface. The above technique warrants further investigation.

\section{Acknowledgements}

Discussions with F.D. Becchetti, G.F. Knoll and P.M. Lister are greatly appreciated. This work was supported in part by the National Science Foundation Grant PHY-8308072.

\section{References}

[1] R.L. Brodzinski, D.P. Brown, J.C. Evans, W.K. Hensley, J.H. Reeves, N.A. Wogman, F.T. Avignone and H.S. Miley, Nucl. Instr. and Meth. A239 (1985) 207.

[2] N. Kamikubota, H. Ejiri, T. Shibata, Y. Nagai, K. Okada, T. Watanabe, T. Irie, $Y$. Itoh, T. Nakamura and $N$. Takahashi, Nucl. Instr. and Meth. A245 (1986) 379.

[3] B. Al-Bataina, Ph.D. Thesis, The University of Michigan (1985) unpublished.

[4] B. Al-Bataina and J. Jänecke, Nucl. Phys. to be published.

[5] J.A. Bearden, Rev. Sci. Instr. 4 (1933) 271.

[6] R.I. Weller, in: The Natural Radiation Environment, eds. J.A.S. Adams and W.M. Lowder (University of Chicago Press, 1964) p. 567.

[7] D. Srdoč, Proc. 2nd Int. Conf. on Low Radioactivity, High Tatras (VEDA Publ. House Slovac Academy of Science, Bratislava, 1980) p. 305.

[8] K. Bunzl and W. Kracke, Nucl. Instr. and Meth. A238 (1985) 191.

[9] D.E. Watt and D. Ramsden, High Sensitivity Counting Techniques (Pergamon, MacMillan, New York, 1964).

[10] Ph. Hubert et al., Nucl. Instr. and Meth. A252 (1986) 87. 